\title{
Ciao merlettà: a volta italianada da muié rendera
}

\author{
Ciao merlettá: crossing cultures - \\ Italian cinema and the sertão
}

Antônio Carlos Amâncio

Como traduzir para o italiano a expressão "Olê, muié rendera", tema musical do filme $O$ Cangaceiro e canção popular do folclore nordestino? Foi esta estupefação de minha amiga napolitana naturalizada que me deu as coordenadas iniciais deste texto. Para chegar a Ciao merlettá ela me descreveu todo o percurso dessa transcodificação linguística: "Olê" seria "ciao", "salve", e "rendeira" é "merlettaia": Ciao merlettaia, ciao merlettà...? O "ciao", que em italiano significa "salve" ("oi") e "arrivederci" ("até logo"), era muito usado em músicas populares ligadas ao trabalho ou à guerra: "Bella ciao", "Ciao amore ciao". O “merlettà" seria

Este artigo é dedicado a Mariarosaria Fabris.

Antônio Carlos Amâncio é mestre e doutor em Cinema pela Escola de Comunicação e Artes (ECA) da Universidade de São Paulo (USP) e professor associado III do Departamento de Cinema e Vídeo e do Programa de Pós-Graduação (mestrado e doutorado) da Universidade Federal Fluminense, Niterói, Brasil (tunicoamancio@gmail.com).

Artigo recebido em 21 de dezembro de 2010 e aprovado para publicação em 24 de fevereiro de 2011.

Est. Hist., Rio de Faneiro, vol. 24, no 47, p. 88-98, janeiro-junho de 2011. 
um neologismo, aceitável porque é possível cortar a sílaba final de uma palavra desse jeito, sobretudo num italiano mais popular.

Essa explicação me serve como uma luva, porque na verdade estou lidando com transferência de códigos, intertextualidades, adaptação, remake. E me serve porque aqui temos um procedimento usual neste gênero de operação de linguagem: aproximamos sentidos, imaginamos associações, sintetizamos ou ampliamos conceitos, montamos correspondências. Tudo em nome de estabelecer uma relação de contato, diacrônica ou sincrônica, com um fato original de cultura no momento de transpô-lo a outro sistema de referências. Pois esta introdução certamente localiza nosso assunto, uma reflexão assistemática sobre o filme $O$ Cangaceiro. Não o original escrito e dirigido por Lima Barreto, com diálogos de Rachel de Queiroz, realizado em 1953 e produzido pela Vera Cruz. Não este, premiado em Cannes como melhor filme de aventura e também como melhor trilha sonora - o clássico "Muié Rendera” - interpretado por Vanja Orico e com coro dos Demônios da Garoa, um filme que teve ampla circulação internacional.

Estaremos falando de outro O Cangaceiro, seu sucedâneo italiano, filmado em 1970 por Giovanni Fago, chamado de Viva Cangaceiro nos Estados Unidos, com locações na Bahia e temática associada ao gênero cinematográfico inventado no Brasil, o nordestern. É ele que nos leva a pensar na questão do remake, no universo expressivo do filme de cangaço e suas apropriações e finalmente no que este filme em particular evoca.

O remake, ou refilmagem, faz parte do universo das interfaces com obras pré-existentes, onde cabem também a adaptação, a referência e a alusão. Em sua proporção industrial, o remake é associado à serie, à continuação ou ao ciclo, a domínios expressivos no interior de uma obra ou na serialização de produtos, temas ou estilos. Um campo determinado por um sistema de repetições, já institucionalizado, que integra procedimentos ligados ao universo legal, de direitos e plágios, ou referencial, de citações e iterações. Constantine Verevis se debruça sobre o assunto, é de seu livro Film remakes que vêm as principais considerações aqui apresentadas.

Citando outros estudiosos, ele identifica três marcas para o remake: a de uma categoria industrial, que lida com assuntos de produção, que envolve estruturas de comércio e negociação de direitos; a de uma categoria textual, que lida com taxonomias e textos, enredos e estruturas; e finalmente a de uma categoria crítica, que lida com recepção, incluindo públicos, com seus processos de reconhecimento e com a consolidação de um discurso institucional. Mas é o uso da variação e da diferença (em relação aos originais) que vai levar a outras categorizações, estabelecidas por Michael Druxman e desenvolvidas por Harvey Roy Greenber: a) a refilmagem estrita, identificável; b) a refilmagem identificável, mas transformada; e c) a refilmagem não identificável, disfarçada (apud Verevis, 
2006: 7). As leituras avançam por esse caminho tortuoso, com variações sobre a similaridade entre obras, a tensão entre inovação e imitação, empréstimos, autoria, questões de autenticidade e de referencialidade, homenagem, imitação ou roubo.

Mas não cabe aqui apenas articular conceitos. O que finalmente encontramos é a perspectiva, também rarefeita, de uma estética da diluição, na qual elementos de variadas formas culturais se dissolvem em outros, de maneira indefinida e inconstante, integrando-se ao universo da nova obra gestada. É de uma espécie de solução química que estamos falando aqui, dispersões que montam um sistema homogêneo, inseparáveis do dispersante. $\mathrm{O}$ resultado desta operação, entretanto, nem sempre é líquido e transparente. Como em qualquer obra de cinema, aliás.

\section{A ira de Deus}

O que motivou Giovanni Fago naquele longínquo 1970 a se debruçar sobre os cangaceiros foi a ideia de que eles eram "bandidos políticos", ou seja, não apenas ladrões, mas rebeldes com posição firmada contra os latifundiários. Segundo o autor, o filme define-se, assim, pela escolha ideológica de seu objeto: uma posição política forte contra a colonização e o imperialismo. Obviamente ele já conhecia O Cangaceiro, de 1953, grande sucesso comercial na época, assim como alguns filmes do Cinema Novo. Fago argumenta que sua intenção não era fazer uma "releitura comercial" desse fenômeno, até porque respeitava certas características da cinematografia brasileira, a qual, primitiva na aparência, era, na verdade, dotada de grande refinamento e inteligência, animada por forte tensão política e impulso à rebelião. Um cinema que correspondia a suas convicções políticas e sociais, frente aos conflitos da América Latina. ${ }^{1}$ Porém, o que define objetivamente o projeto de produção é a aquisição dos direitos da canção do velho filme $O$ Cangaceiro.

Essa perspectiva comercial vai ser um dos únicos elementos de ligação entre a produção italiana e uma larga tradição brasileira de filmes de cangaço. Há toda uma linha de parentesco sustentando esta arquitetura, que começa nos filmes de cowboys, no bangue-bangue, nos filmes de faroeste.

Se o western - considerado o cinema americano por excelência num texto de André Bazin, publicado em 1953 (Bazin, 1991: 204) - sofreu contaminações passageiras, o que, segundo ele, não deve ser lastimado, também resistiu, mantendo os símbolos e signos que o fizeram mitológico. O cenário, a paisagem, a cavalgada e a briga, as referências históricas, "o grande maniqueísmo épico que opõe as forças do Mal aos cavaleiros da justa causa”, a Mulher em sua relação com 
a Virtude, até mesmo os cavalos, são todas marcas pelas quais se expressa uma ética da epopeia e mesmo da tragédia. Marcas que geram um estilo de mise-en-scène e transparecem numa composição da imagem, os grandes planos de conjunto, a quase abolição do primeiro plano, o travelling e a panorâmica que "negam o quadro da tela e restituem a plenitude do espaço" (Bazin, 1991: 206). Um gênero dotado de situações excessivas, de exagero dos fatos e de uma inverossimilhança ingênua, fundado entretanto, numa moral que o justifica.

Diluindo-se pelo mundo, o western passa pelo Brasil, onde assume a forma do filme de cangaço, tematizando elementos da história local e acrescentando uma tintura cultural própria. O Cangaceiro, de Lima Barreto, é a matriz que vai moldar um longo ciclo que se condensa entre os anos 1950 e 1970, com tonalidades diversas, que vão do filme de aventuras à comédia erótica e que promove um retorno pós-modernizado na virada do milênio. ${ }^{2}$

Walnice Nogueira Galvão (2005) associa o fenômeno da sertanização, no qual o representante mais marcante é o cangaceiro, ao regionalismo literário dos anos 1930, às artes plásticas do expressionismo social e engajado dos anos $1940 \mathrm{e}$ ao faroeste americano, como de praxe, bem como a uma certa composição gráfica do cinema mexicano, com suas paisagens desérticas, seus cactos na caatinga, $o$ gado à solta tocado por cavaleiros desombreros. Rica iconografia calcada no inacabado Que Viva México, de Eisenstein, e suas contrafações. ${ }^{3}$ Um circuito de referências que passa obrigatoriamente por Elia Kazan e seu Viva Zapata de 1952, e chega ao western de Lima Barreto, rodado em Vargem Grande do Sul, no interior de São Paulo, com seu contrastante preto e branco, sua luz ofuscante, seu emblemático contraluz dos cangaceiros no pôr do sol, quando o cangaço vira pura mitologia, depois de desaparecido do mundo social desde a década de 1940, com a morte de Corisco.

O Cinema Novo vai retomar o imaginário sertanejo do western, relido numa tecla nacional e popular, e vai, ainda segundo Walnice Galvão, ressemantizá-lo num arco cinematográfico em vários segmentos. O primeiro segmento era aquele temporalmente próximo ao golpe militar e aí estará o também emblemático Deus e o diabo na terra do Sol, junto com Vidas secas, Os fuzis e A hora e a vez de Augusto Matraga, certamente o conjunto mais visitado e seguramente, o mais próximo do olhar de Giovanni Fago. O dragão da maldade contra o santo guerreiro, anos depois, completa o grupo (Galvão, 2005: 87).

Glauber já preconizara, em 1957, a autonomia do cinema perante as outras manifestações artísticas, assim como Bazin, em 1953, caracterizara o western como "filho autêntico e puro do cinema", no qual o herói se dilui no gênero, que progride em concentração expressiva (Rocha, 1997). Esta é certamente uma boa referência para pensarmos a relação western-cangaço-spaghetti e vermos como $O$ Cangaceiro de Fago se comporta frente a tantas hibridações. 


\section{Compañeros}

Na Itália, o western-spaguetti chegou num momento de crise da indústria cinematográfica e dos grandes estúdios. No entanto, para que lembremos que a releitura do western expandiu-se por toda parte e não foi só uma invenção italiana, o primeiro faroeste europeu é, na verdade, alemão. Refiro-me a $O$ tesouro dos renegados, de 1961, as aventuras de um índio chamado Winnetou, filmado na antiga Iugoslávia por Harald Reinl (Carreiro, 2009). De todo modo, na Itália foram rodados mais de 600 filmes nas décadas de 1960 e 1970, insuflando um pouco de oxigênio ao gênero, já desgastado, através do fomento à aparição de uma galeria de novos cineastas-autores, da composição de um elenco estelar multinacional, sem o peso da história de sua matriz americana. Boa parte dos cineastas possuía inclinações à esquerda, valendo-se das mitologias do gênero e das revoluções (principalmente da mexicana, aproveitada à exaustão), uma levada pop, uma música onipresente, expansão do campo temático das histórias, maxi-valorização da paisagem e dos recursos técnicos contemporâneos, do zoom intenso à moldura dos rostos em primeiro plano, valorizando a profundidade de campo, e mais as explosões apresentadas em uma montagem lacônica, dando sempre a impressão de faltar alguns fotogramas.

Giovanni Fago mantém, desse universo, a moldura e a embalagem, mas vai buscar outros conteúdos. Ele se cerca de muitos cuidados. Seu roteirista é Bernardino Zapponi, que trabalhou com Fellini em Satyricon, Os palhaços, Roma, Casanova e muitos outros. A música cabe a Riz Ortolani, compositor experiente, com participação em mais de duzentas trilhas. Conta ainda com a colaboração do fotógrafo Alejandro Ulloa, que trabalhara com Sergio Corbucci, Umberto Lenzi, Enzo Castellari e muitos outros. Uma equipe afiada! O ator principal, Tomas Milian, vinha de uma carreira marcante no western-spaghetti, $\mathrm{e}$ no mesmo ano participa de Compañeros, um filme de Sergio Corbucci, na companhia de Franco Nero. Esse filme que, por várias razões, guarda muitos pontos de contatos com $O$ Cangaceiro, entre os quais o de que ambos foram co-produções ítalo-espanholas.

Ao som de "Muié rendera", a trama tem início com um ataque da polícia a um bando de cangaceiros, sitiados num vilarejo. $\mathrm{O}$ coronel Minas coordena o extermínio do bando de Firmino... e para seu azar, nesta confusão a vaca do camponês Expedito é fuzilada. Expedito é recolhido pelo beato Julião das Miragens, que lhe ensina o valor da justiça, de um Cristo que usa o chicote e pune os maus, distribuindo o que comer e o que beber entre os pobres, e lhe anuncia que ele, Expedito, é o enviado do Senhor, sob o nome de Redentor!

Um acaso, um personagem que é levado a uma situação inusitada, um protetor que o acolhe e instrui, tudo isso compõe uma situação modelar. Mas a 
caracterização física dos personagens é quase caricata, os diálogos são trespassados por uma ingenuidade cômica que, se não compromete a verossimilhança da narrativa, aponta para um registro de tonalidades mais associadas à comédia de costumes italiana e ecos de Brancaleone.

Expedito prega nos vilarejos, convocando apóstolos em meio ao desinteresse da população. Mas quem aparece em sua frente é o bando do Diabo Negro, a quem Expedito se apresenta como o novo rei do cangaço, sagrado pelo arcanjo Gabriel para combater pela verdade e a justiça, a cruz e o facão na mão. Convidado a integrar o grupo, outra das situações-modelares do gênero, Expedito recusa e promete ter sua própria gente. A frase do cangaceiro soa quase como ameaça quando estabelece, metaforicamente, a hierarquia das relações sociais: "um facão é mais longo que a mão, mas um fuzil é mais longo que um facão”. E Expedito responde a ela se livrando da cruz.

Em Angicos, na festa cívica de inauguração da bateria de canhões da cidade, com a presença do cardeal, vemos então o dissimulado Expedito na situação de paralítico, sentado sobre um carrinho de rolimã, mas seu jeito debochado vai levá-lo à prisão, determinada pelo coronel Minas. Na cadeia, ele constituirá seu bando, depois de demonstrar sua astúcia e explodir os canhões. Expedito/Redentor, com as armas que consegue, mata os que o desobedecem, parte para o sertão e ganha notoriedade, passando a ser procurado.

É então que se apresenta sua contrapartida dramática. Num vilarejo, chega um automóvel de classe, dirigido por um holandês louro e elegante, de botas de cano alto e foulard. Munido de livros, mapas e de instrumentos, o homem dirige-se à praia. A população olha com curiosidade o automóvel diferente. Voltando, o homem encontra seu carro totalmente depenado. Só sobrou a estrutura de ferro. Enquanto ele se indaga o que teria acontecido, cresce sobre seus livros a sombra do Redentor! No contraplano, em contraplongée, Redentor aparece santificado, envolto por um halo solar. O cangaceiro intima o viajante a ler para ele um longo romance sobre o mar. E daí, deste contraste entre a força, a violência e a submissão física e a educação, a leitura e os modos cultivados do europeu vai se estabelecer o elo central da relação entre os dois homens. Esta é a trama principal, denunciada por alguns críticos como sustentada por um homoerotismo casto, demarcando um campo pouco explorado até então pelo gênero e suas derivações, normalmente pré-determinados pelo machismo e pela virilidade.

O holandês Vincenzo Helfen aproveita-se da atração que exerce sobre o camponês analfabeto e desenvolve essa amizade de acordo com sua estratégia. Torna-se a interface do cangaço com o poder local, e mesmo internacional, do qual será o representante, como veremos, e que implica finalmente a exploração de jazidas de petróleo e a maximização de seus ganhos agregados, tais como a 
ocupação de mão de obra local e a mais intensa circulação financeira. O holandês é relacionado ao progresso, e o cangaceiro vai ser seu associado contra o atraso do sertão.

Essa oposição qualifica a temática da transição do rural ao urbano, do pré-capitalismo ao capitalismo de ponta, permitindo, assim, que o filme seja inscrito na representação da modernização e da evolução industrial do Nordeste brasileiro. $\mathrm{O}$ avanço_do segmento agroexportador para o de prospector de petróleo se dará na realidade com a instalação da primeira refinaria do Brasil, a Landulfo Alves em Mataripe, no Recôncavo baiano, em 1956, operações que antecedem o futuro polo petroquímico de Camaçari. ${ }^{4} \mathrm{O}$ filme expressa, portanto, uma situação alegórica e quase premonitória, já que estamos presumivelmente nos anos 1930. A pertinência da objetivação do petróleo como mote propulsor da trama, guarda certamente, relação com o olhar contemporâneo dos anos 1970.

Dramaticamente, esse acerto é negociado por Helfen que vai possibilitar a ascensão de Redentor como autoridade no sertão, já que este, depois de perseguido, passa a compor com as autoridades e extermina os bandos rivais para que a empreitada do petróleo possa prosseguir. $O$ Redentor torna-se a ponta de lança de um acordo que engloba o poder civil local, os militares, a Igreja e os interesses estrangeiros, representados e patrocinados não só por Helfen e sua companhia petrolífera, mas também por um inverossímil bando de gangsters, como que saídos de uma peça de Bertolt Brecht.

Não faltam emboscadas, tiroteios e mobilizações de tropas, em que, às vezes, um tom contemplativo desarruma a potência de um filme de ação. Como, por exemplo, na caminhada ao pôr do sol, onde quem se alinha na contraluz, em postura desconstrutora e modernizante, são o destacamento militar e mais tarde, o negociador Helfen, num pungente adeus à iconografia do velho sertão.

Essas são transgressões às marcas do gênero, assim como o são a repartição equânime do tempo dramático entre os dois personagens centrais, o louro europeu e o mestiço Expedito, em encontros e confrontos, negociação de armas e tratados de paz, jantares de apresentação, concessões de salvo-conduto e danças de forró em ritmo acelerado, quase de samba. É nessa ocasião que, em um rápido plano, Expedito é visto beijando uma empregada uniformizada, único acesso dramático do universo feminino em relação direta com um dos dois protagonistas masculinos. Um beijinho e só, o máximo de relação hetero permitida.

Os elementos da representação, associados ao gênero e suas diluições, são bastante completos, não faltando os duelos de facão, as feiras, com cantadores e fotógrafos, a relação de subserviência dos camponeses e da própria Igreja. $\mathrm{Na}$ história, então, Redentor ganha uma fazenda que quer transformar num paraíso terrestre, prova de sua entrega aos desígnios divinos. 
A trama entra em seu desenvolvimento final, que implica no jorro do petróleo e na aparição dos gangsters americanos comandados por Frank Binaccio e seus homens, fugitivos do governo republicano de Calvin Coolidge por evasão fiscal. O governador decide matar Expedito e, pagando um bom preço, pede que os gangsters lhe tragam a cabeça do cangaceiro. Sentindo-se traído, Expedito culpa o holandês, que aparece e explica que o governador mandou matar todos do vilarejo, responsabilizando-os por acolher cangaceiros. A vila assim foi evacuada para a perfuração dos poços. Helfen assume sua parte de culpa e denuncia a negociação com Binaccio. É esta traição, que o holandês faz ao governador e ao seu país, que salva o cangaceiro. Helfen define aqui seus afetos e assume junto ao Redentor sua redenção. Esta união, movida por vingança, provoca a morte dos gangsters e do governador e o apaziguamento da região.

Encontro na duna, Expedito e seu bando, Vincenzo Helfen partindo de vez. Na despedida, Helfen confessa sua simpatia e cumplicidade com o cangaceiro, que admite não ser o enviado que imaginara. Mas o holandês o conforta, dizendo que ele tinha cumprido muito bem o seu papel. Happy-end. Expedito volta para a estrada, Helfen provavelmente para a Holanda.

O filme termina de modo convencional, centrado no selo da amizade entre os dois protagonistas. $\mathrm{O}$ grupo, finalmente conscientizado, continua a atuar e isso é uma possibilidade de novas aventuras, como num western tradicional. Vence o pressuposto violento e vingador, mas ético, do bandido, sob o arrependimento do adversário.

Giovanni Fago conta que o filme fez sucesso na Itália e no resto da Europa, mas só chegou à América Latina três ou quatro anos depois (por conta de sua perspectiva política, foi considerado perigoso). $\mathrm{O}$ cineasta renega a etiqueta de western, considerando-a inexata, preferindo defini-lo como um filme político de aventuras.

A apropriação do nome $O$ cangaceiro e de seu universo mitológico estabelece uma conexão obrigatória com a obra original e este gesto não pode ser considerado, de nenhuma maneira, como ingênuo, desprovido de intencionalidade, inclusive comercial. Os direitos da canção original ${ }^{5}$ são o aval desta operação.

Somos levados a buscar na obra italiana elementos presentes no filme de Lima Barreto, mas nos deparamos com traços soltos, pertencentes ao gênero, e quase nenhuma marca do original. O impulso criador do western clássico, de sua apropriação pelo Cinema Novo e pelo spaghetti, perde-se num pastiche sem alma. É essa estética da diluição sucessiva que leva a um processo de abrandamento das especificidades de cada forma cinematográfica utilizada, solvendo num texto comum o que foi, um dia, ousadia ou expressão dinâmica. 
1. Entrevista do diretor, bônus do DVD O Cangaceiro, coleção Lâge d'or du cinéma européen. Wild Side films

2. O Almanaque, boletim eletrônico da jornalista Maria do Rosário Caetano dá conta, em 15/06/2010, de várias produções sobre o cangaço em andamento. Homero Olivetto, Wolney Oliveira, Hermano Penna, Geraldo Sarno e Ícaro Martins preparam filmes sobre o cangaço ou sobre cangaceiros. A filiação prossegue.

3. Filme feito entre 1930 e 1932 por Eisenstein e que gerou algumas montagens executadas sem sua presença e renegadas pelo cineasta: Thunder Over Mexico, Ei-

\section{Referências bibliográficas}

BAZIN, André. O western ou o cinema americano por excelência. O Cinema: Ensaios. São Paulo: Brasiliense, 1991.

CARREIRO, Rodrigo. Do desprezo à glória: o spaghetti western na cultura midiática. Baleia na Rede, vol. $1, \mathrm{n}^{\circ} 6$, ano VI, dez/2009 - (http://www.marilia.unesp.br/ Home/RevistasEletronicas/BaleianaRede/ Edicao06/4_Do_desprezo_a_gloria_wester n_spaghetti.pdf)

GALVÃO, Walnice Nogueira. Metamorfose do sertão. In: CAETANO, Maria do senstein in Mexico, Death Day e Time in the Sun.

4. Carta IEDI n. 201 - O Futuro do Pólo Petroquímico de Camaçari - Publicada em 31/03/2006 - http://www.iedi.org.br/cgi/ cgilua.exe/sys/start.htm?infoid $=2037 \&$ si $\mathrm{d}=20 \& \mathrm{tpl}=$ printerview - acessado em $27 / 09 / 2010$

5. A canção, cuja autoria foi atribuída a Zé do Norte, teve grande repercussão internacional. Foi gravada por um naipe de músicos que vai dos Demônios da Garoa, em 1953, até Joan Baez, em 1964, passando por Astrud Gilberto e muitos outros.

Rosário (org). Cangaço: o nordestern no cinema brasileiro. Brasília: Avatar, 2005.

GOMES, João Carlos Teixeira. Glauber Rocha, esse vulcão. Rio de Janeiro: Nova Fronteira, 1997.

ROCHA, Glauber. O western: uma introdução ao estudo do gênero e do herói. Mapa, $\mathrm{n}^{\circ} 1$, Salvador, ABES, 1957.

VEREVIS, Constantine. Film remakes. Edinburgh: Edinburgh University Press Ltd, 2006. 
Referências filmográficas

A hora e a vez de Augusto Matraga (BRA, 1965, dir: Roberto Santos)

Casanova de Fellini (ITA, 1976, Federico Fellini)

Compañeros (ITA, 1970, dir: Sergio Corbucci)

Deus e o diabo na terra do sol (BRA, 1963 , dir: Glauber Rocha)

O cangaceiro (BRA, 1953, dir: Lima Barreto)

O cangaceiro (ITA, 1970, dir: Giovanni Fago)

O dragão da maldade contra o santo guerreiro (BRA, 1969, dir: Glauber Rocha)

$O$ incrível exército de Brancaleone, (ITA, 1965, dir: Mário Monicelli)

O tesouro dos renegados (ALE/ITA/IUG, 1961, dir: Harald Reinl)
Os fuzis (BRA, 1964, dir: Ruy Guerrra)

Os palhaços (ITA, 1970, Federico Fellini)

Que viva México (MEX, 1932, dir: Grigori Aleksandrov, Sergei M. Eisenstein)

Roma de Fellini (ITA, 1972, Federico Fellini)

Satyricon(ITA, 1969, dir: Federico Fellini)

Thunder over Mexico (EUA, 1933, dir: Sol Lesser)

Time in the Sun (EUA, 1939/40, dir: Mary Seton)

Vidas secas (BRA, 1963, dir: Nelson Pereira dos Santos

Viva Zapata (EUA, 1952, dir: Elia Kazan)

\section{Resumo}

O cangaceiro é personagem marcante no cinema brasileiro, ligado a uma dada mitologia do sertão e a uma perspectiva regional. Associado ao filme de cangaço, reapropriação do western, mereceu poucas representações em cinematografias estrangeiras e por isto causa surpresa a produção, na Itália de 1970, do filme O cangaceiro, de Giovanni Fago, que pretendemos analisar à luz de algumas interfaces com elementos da cultura brasileira. Consideramos a dupla apropriação do gênero (western, filme de cangaço, western spaguetti), e as atualizações temáticas, pensando as transgressões aos modelos canônicos, a partir de uma singular absorção de conteúdos historicamente definidos.

Palavras-chave: filme de cangaceiro; releitura cinematográfica; representações estrangeiras. 


\begin{abstract}
The cangaceiro (bandit) is an outstanding character in the Brazilian cinema, connected to a given mythology of the sertão and to a regional perspective. Associated to the cangaço movies, reassigning the western genre, it deserved few representations in foreign cinematographies. We deal with one Italian production, $O$ cangaceiro, made in 1970 by Giovanni Fago, which we intend to analyze through some interfaces with elements of the Brazilian culture. We consider the double appropriation of the genre (western, cangaço's films, western spaghetti), and the thematic updates, thinking the transgressions to the canonical models, from a singular absorption of historically defined contents.
\end{abstract}

Keywords: bandit's movie; cinematographic rereading; foreign representations.

\title{
Résumé
}

Le cangaceiro est un personnage remarquable dans le cinéma brésilien, lié à une certaine mythologie de l'arrière-pays, dans une perspective régionale. Associé au film de cangaço, réappropriation du western, il n'a pas eu une représentation forte dans le cinéma étranger. Comme ça c'est surprenante cette production italienne appelée $O$ cangaceiro, réalisée par Giovanni Fago en 1970. Nous allons l'analyser par certaines interfaces avec des éléments de la culture brésilienne, l'appropriation du genre (western, film de cangaço, western spaghetti), et la mise à jour thématique, pour penser les transgressions au canon, mélangeant des contenus définis historiquement.

Mots-clés: film de cangaceiro; relectures filmiques; représentations de l'étranger. 